\title{
Carried or Defeated? Examining the Factors Associated with Passing School District Bond Elections in Texas, 1997-2009
}

\author{
Alex J. Bowers ${ }^{2}$ \& Jooyoung Lee \\ Teachers College, Columbia University \& The University of Texas at San Antonio
}

\begin{abstract}
Purpose: Across the United States, a large percentage of school districts are in need of facility improvements to provide safe and adequate buildings to facilitate student learning. To finance new construction, school districts traditionally have put proposals before local voters to fund construction through issuing long-term bonds to finance near-term construction. However, past literature indicates that there are few variables that are associated with bond election outcomes that are under the influence of school administrators. The purpose of this study was to examine the factors most associated with passing or failing a school district capital facility finance bond in the state of Texas from 1997 through 2009.

Research Methods: We analyzed all proposed school bonds in Texas from 1997-2009, $n=2,224$, using a logistic regression discrete time hazard model to model the probability of passing a bond on the first, second or third attempt, while controlling for multiple types of variables such as bond, district and community characteristics, as well as specific election characteristics.

Findings: We found that the first attempt of a bond is the mostly likely to succeed, as well as bonds that propose renovations and debt refinancing, or are at the top of the ballot. Also, while percent population over age 65 was negatively related to bond passage, percent Asian and Hispanic students was positively related.

Implications for Research and Practice: Using past research and our findings, we propose a mediated model of school bond passage, and provide specific recommendations for administrators looking to pass needed facility construction bonds, including focusing on passing the bond on the first attempt and proposing only a single bond that includes all requests.
\end{abstract}

Keywords: Bond issues, longitudinal studies, educational finance, facilities, school finance, school district spending, election campaigns, debt

\section{INTRODUCTION:}

In the United States, PK-12 public school districts generally finance the construction of new school facilities through voterapproved local school bond elections, in which the school district proposes to issue a certain amount of long-term debt to fund the near-term construction of new schools, facilities and renovations

\footnotetext{
1 This document is a pre-print of this manuscript, which was originally published in the journal Educational Administration Quarterly. Citation: Bowers, A.J., Lee, J. (2013) Carried or Defeated? Examining the Factors that Predict School District Bond Elections in Texas, 1998-2009. Educational Administration Quarterly, 49(5),732-767. doi: 10.1177/0013161X13486278

${ }^{2}$ Teachers College, Columbia University; Bowers@tc.edu; 525 W. $120^{\text {th }}$ Street, New York, New York 10027.

ORCID: 0000-0002-5140-6428, ResearcherID: C-1557-2013
}

(Duncombe \& Wang, 2009; Sielke, 2003; Sielke, Dayton, Holmes, \& Jefferson, 2001). Studies on the estimates of the unmet school capital construction needs across the states have indicated that the majority of U.S. school districts are in need of at least some renovations to their existing schools, while a large percentage need new schools constructed to meet the safety, security and basic facility requirements of their school districts and communities (Arsen \& Davis, 2006; Crampton, 2003; Crampton, Thompson, \& Hagey, 2001; Holt, 2009; NCES, 2000). While there is a fairly wide literature aimed at school and district administrators with normative models from "lessons learned" to suggestions on "how to pass your bond" (Bauscher, 1993; Boschee \& Holt, 1999; Davis \& Tyson, 2003; Dunne, Reed, \& Wilbanks, 1997; Holt, 2009; Holt, Wendt, \& Smith, 2006; Ingle, Johnson, \& Petroff, 2011; Ingle, Johnson, \& Petroff, 2012; Johnson \& Ingle, 2009; Kastory \& Harrington, 1996; Kraus, 2009; Lentz, 1999; Mathison, 1998) recent empirical research is sparse on exactly what factors are most associated with passing or failing a school facilities bond.

\section{A History of Research on School Bond Elections}

Interestingly, a fairly large amount of research on the factors most associated with passing or failing a school bond was conducted in the U.S. during the 1960s and early 1970s, as the "baby-boomer" generation matriculated through the public school system and districts needed to build schools to accommodate the demographic shifts in their communities, culminating in large summary studies in the mid-1970s (Alexander \& Bass, 1974), including the extensive literature review and theory-building study by Piele and Hall (1973). In their review, they synthesized the work of over one hundred different studies and worked to create a theory of voter behavior as it relates to passing school bonds. From a theory perspective, they postulated that there were two major determinants to the outcome of a school referenda; who was most likely to participate versus who was most likely to vote "yes" (Piele \& Hall, 1973). This included four different variables as they relate to the voter, including voter age, socio-economic status, education, and ethnicity.

First, middle to older-aged voters were more likely to participate. Conversely, they were also more likely to not vote in favor of the bond, due in part to not having children currently in the school and being more likely to be in general opposition to new taxes while younger voters were more likely to have children in the schools and support new facilities, relying on a few central studies, such as (Campbell, Converse, Miller, \& Stokes, 1964b; Lipset, 1963). Second, higher socio-economic status related to both stronger participation and likelihood of voting yes, as did the third variable, higher education levels (Alexander \& Bass, 1974; Carter \& Ruggels, 1966; Minar, 1966). And fourth, Piele and Hall (1973) found across multiple studies that by ethnicity, white voters were more likely to participate, while African American voters were more likely to vote yes, such as (Campbell, Converse, Miller, \& Stokes, 1964a; Lipset, 1963). These cross-study findings provided evidence to help describe generalizations about participation and favorable voting habits, however they provided little in the way of 
direction for districts wishing to pass a bond, since the variables related to participation and yes voting were both very similar. Thus, according to the theory postulated by Piele and Hall, because participation is closely linked to yes voting, attempting to positively influence the bond election by working to increase voter turnout would "produce a relatively greater representation of those less likely to favor school financial elections... as an increase in participation yields a more representative sample of the total eligible population" (Piele \& Hall, 1973) (p.151). Thus, Piele and Hall also provided a theory focused on the bond election as the unit of analysis as a means to provide malleable variables that could be used to help increase the likelihood that voters would support the school bond.

Piele and Hall (1973) provided evidence in their review towards a model of bond passage that included district and election characteristics. Interestingly, for district characteristics, they found that district enrollment as well as the pupil/teacher ratio was not related to election outcomes, focusing on two main studies, (Beal, 1966; Minar, 1966). For the characteristics of the election, these studies found that the time of year of the election was unrelated to the election outcome while evidence on the effect of the size of the bond proposal (in dollars) was mixed, with some studies showing no effect while others demonstrated a significant negative effect (Beal, 1966). In addition, as to the effect of the wording of the bond and what was requested, findings across studies were mixed, in that some studies argued that there was no effect (Beal, 1966), while others argued that there may be an effect, but only in small districts with specific bond requests (Barbour, 1966).

Thus, in sum, Piele and Hall (1973) painted a fairly discouraging picture of the ability of a school district to influence the outcome of school bond elections, other than in the negative. Piele and Hall set forth an apparent paradox for school districts looking to pass their bond. They theorized that community support for a local bond election in a school district is constant, with fairly intact groups that will vote yes or no, based mostly on demographics, while at the same time there was little evidence to show that factors under the influence of the district (election timing, bond amount, purpose, and wording) were associated with final bond outcomes. However, while Piele and Hall's (1973) study was a foundational and exhaustive study at the time, there are multiple issues with their work. First is that the study is dated, with the vast majority of the studies they cite analyzing data from the 1950s and 1960s. While not a problem in-and-of itself, the communities included in their study have experienced broad changes in their demography, as has the entire U.S., over the intervening 50 years. Second, the analyses included in their study focused almost exclusively on descriptive statistics only, with few studies using inferential statistics. Third, sample sizes were relatively small, intact and cross-sectional across the vast majority of their studies reviewed, hampering the ability to generalize across contexts and into the present.

\section{Recent Research on Passing or Failing School District Facility Bonds}

Since Piele and Hall (1973), literature on the factors most associated with passing or failing school district bond elections has been sparse. However, a small and growing body of recent research has begun to focus on updating this research domain on facility bonds (Beckham \& Maiden, 2003; Bowers, Metzger, \& Militello, 2010a, 2010b; Johnson \& Ingle, 2009; Sielke, 1998; Zimmer, Buddin, Jones, \& Liu, 2011; Zimmer \& Jones, 2005). As a way to begin to address the main tension described in Piele and
Hall's theory of the constant ratio of a community's yes voters combined with little evidence that election or bond characteristics influence bond outcomes, the more recent research has turned from the voter as the unit of analysis, as it was in Piele and Hall (1973), to the bond as the unit of analysis. This has allowed recent researchers to focus on the factors most associated with passing or failing a school bond, rather than focus on theories around school district median voter behavior (Berkman \& Plutzer, 2005; Dunne, et al., 1997; Fort, 1988; Fort \& Bunn, 1998; Rubinfeld, 1977), such as rational choice voter theory (Blais, 2000), in an attempt to build theory specifically associated with school bonds and to inform administrator practice to help schools find the funding they need to build adequate facilities for their students. Thus, this literature has two overlapping constituencies, the researcher focused on the theory of why and how bonds come to be passed, and the practitioner looking for specific generalizable, and applicable findings that they can apply to help them pass their bond, or at the least decrease its risk of defeat at the election polls.

The more recent literature, while sparse, has used logit or probit regression analysis and longitudinal datasets to examine three main aspects of passing or failing school capital facility construction bonds including 1) longitudinal analysis, 2) examining district and community factors, and 3) examining specific aspects of the bond or election. First, recent innovations in longitudinal data analysis has allowed researchers to include the analysis of large multi-year state-wide datasets, reducing sample bias since the entire population of bonds in a state is examined over a specified period, and to examine the practice of school districts floating and then refloating a bond that failed on the first attempt. In many instances, once a bond has failed, a school district will attempt the bond election again, in the hopes that the electorate is more favorable on a different day (Dunne, et al., 1997). In a study of 169 Michigan bonds between 1993 and 1994, Sielke (1998) found that the number of attempts was not significant on the likelihood of passing a bond, controlling for other variables in the model, such as the district property value, expenditures, debt payments, and amount of the bond. However, Bowers et al. (2010a) argued that including number of attempts in a logistic regression did not appropriately control for the conditional nature of the data represented by floated and then refloated bonds. The data is conditional because a bond is only eligible to be a "refloat" if it has failed previously. Thus, these authors used discrete-time hazard modeling to estimate the effect of floating and then refloating a failed bond a second, or even a third time, analyzing all 505 bonds proposed in Michigan from 2000-2005 (Bowers, et al., 2010a), and then expanding the study to all 789 Michigan bonds proposed between 1998-2006 (Bowers, et al., 2010b). They found that a bond is most likely to pass on the first attempt, controlling for other variables in their model. This finding expands the theory of bond passage to longitudinal models, examining district bond and election behavior, providing an avenue to begin to address the malleable factors of a bond that are under the control of district administration that may be associated with bond passage, such as floating or refloating.

Nevertheless, as the second main thread across the recent studies, community factors have been shown to be significant predictors of school bond passage, with some communities experiencing favorable election climates, while others disproportionally experience what could be termed hostile voting environments in which the most likely outcome for the bond is failure. In replication of Piele and Hall (1973), the socio-economic status of the school district was shown in the Michigan studies to be positively related to bond passage, such that as SES increases 
across the community, the odds of passing a bond increase (Bowers, et al., 2010b; Sielke, 1998). In replication of the district SES finding, Zimmer et al. (2011) examined community median income and community poverty in their study of 343 bonds in Michigan from 1999-2001, finding similar significant effects on percent yes voters and bond passage. Also in replication of Piele and Hall (1973), recent studies confirmed that district enrollment was not a significant predictor of bond passage, including the Michigan studies (Bowers, et al., 2010b; Sielke, 1998; Zimmer, et al., 2011) as well as a study of all 522 bonds in Oklahoma between 1995 and 2000 (Beckham \& Maiden, 2003). Interestingly, the long-term debt of the district has been shown to be a positive and significant predictor of bond passage (Bowers, et al., 2010b; Zimmer, et al., 2011; Zimmer \& Jones, 2005).

Continuing with a focus on Michigan, Zimmer and Jones (2005) examined 906 school bonds in Michigan from 1990 through 1998, and showed that the more long-term district debt, the more likely a district is to pass their bond, with this finding recently replicated with Michigan bonds from 1999-2001 (Zimmer, et al., 2011). Bowers et al. (2010b) confirmed and updated this finding with more recent data from the 2000's in Michigan (1998-2006), postulating that districts with higher amounts of long-term debt are more favorable towards passing school bonds, since they have demonstrated in the past that they are willing to tax themselves in support of district requests. Furthermore, district locale has been shown to be strongly related to bond passage rates in Michigan (Bowers, et al., 2010a, 2010b; Zimmer, et al., 2011; Zimmer \& Jones, 2005), with rural districts experiencing lower odds of passing a bond controlling for the other variables in the models, while small towns appear to experience the worst odds of all. For Michigan, these differences in bond passage rates between district locales may be due in-part to the competition between school districts brought about through Michigan's competitive student choice market (Arsen, Clay, Devaney, \& Fulcher-Dawson, 2005; Arsen \& Davis, 2006; Militello, Metzger, \& Bowers, 2008). And finally, from the perspective of the community environment, while Piele and Hall (1973) detailed findings around the significant demographic factors of voter age as well as ethnicity, only Zimmer and Jones (2005) and Zimmer et al. (2011) included percent of population over age 65 in their models and found that it was negative and significant in the late 1990s, but was not significant in Michigan from 1999-2001, examining the effect of the perceived negative impact of older voters on school finances (Berkman \& Plutzer, 2005; Button \& Rosenbaum, 1989; Duncombe, Robbins, \& Stonecash, 2003; Glass, 2008). Zimmer et al. (2011) is the only recent study to include ethnicity, and found no relationship between student ethnicity and bond passage in Michigan. In addition, Bowers et al. (2010b) found that the percent of the population with only a high school degree was negatively related to bond passage in Michigan from 1999-2006, while Zimmer et al. (2011) found no relationship between bond passage and the percent of the community with a bachelor's degree or higher in Michigan from 1999-2001.

The final main thread across the recent studies on school bond elections has focused on six main election characteristics, including refloats, amount of the bond, bond wording, day of the year, voter turnout, and ballot number. It is the election characteristics that are most under the control of the district administration. First, as outlined above, the recent research on refloating a bond has demonstrated a significant negative effect on refloats. In comparison, other election characteristics have not been as clear-cut. The second main election characteristic studied has been the associated influence of the size of the bond issue on the probability of passing a bond. Results were unclear in the review by Piele and Hall (1973), with some studies noting a significant negative effect, while others demonstrated no relationship. More recently, from the Michigan studies, Sielke (1998) did not find a relationship with two years of bond data from 1993-1994. However, amount of the bond was negative and significant in two of the more recent Michigan studies from 1999-2006 that included the variable (Bowers, et al., 2010a, 2010b) but was not significant in Michigan from 1999-2001 (Zimmer, et al., 2011) or in Oklahoma (Beckham \& Maiden, 2003), indicating that controlling for the other variables in the models, larger bonds may fail more often when examining long-term data.

Third, as noted by Piele and Hall (1973), that while a school district may have specific needs that must be included within a bond proposal, bond wording is one of the most easily controlled aspects of the bond, however it has not been the subject of many of the recent studies, except for Beckham and Maiden (2003) and Zimmer et al. (2011). In the Beckham and Maiden (2003) study, they aimed to assess the effect of including wording about technology on the probability of passing school facilities bonds in Oklahoma between 1995-2000, and found that including wording pertaining to technology on the bond was associated with a small but significant increase in the probability of passing the bond. However, Bowers et al. (2010b) attempted to replicate this finding for Michigan bonds, and found that inclusion of technology wording was not significantly related to the likelihood of bond passage. Zimmer et al. (2011) examined bond wording in Michigan from 1999-2001 and showed that controlling for the other variables in their model, bonds that contained wording pertaining to maintenance and operations had an increased probability of passing, while bonds with wording pertaining to band and art equipment, as well as parking lots, had a higher probability of failing. These studies indicate that while bond wording may be a very interesting variable, especially for administrators looking to pass their bonds, more study is needed since it may be a context-specific variable.

Furthermore, the fourth election characteristic considered in the recent research has been day of the year of the election. Piele and Hall (1973) noted that they could find no evidence that there was any better time during the year to float a bond over some other time of year. In contrast, Bowers et al. (2010b) tested "day of the year" in their model, and showed that for Michigan from 19982006, there was a small but significant positive relationship between passing a bond and having the election later in a calendar year. Dunne et al. (1997) demonstrated that out of 609 bond elections in Oklahoma between 1988 and 1992, elections were more likely to be held during the school year; however they did not test an association with election outcome. Fifth, voter turnout was strongly negatively related to bond passage in the Michigan model (Bowers, et al., 2010b), confirming Piele and Hall (1973). And sixth, Bowers et al. (2010b) tested the ballot number of the proposed bond, for the first time across the research literature on school bond passage, and found that bonds that were the first or only issue on the ballot had significantly greater chances of passing, in comparison to bonds that were further down the ballot, postulating a model of "voter fatigue" as voters appear to be less likely to vote for multiple bonds on the same ballot.

Similar to the above literature on bonds, a concurrent line of research includes bonds as just one of many types of budget referenda that may be brought before school district voters in states 
such as New York, Ohio and California, which may also include recurring and non-recurring costs and revenue requests through new taxes in addition to construction bonds (Berkman \& Plutzer, 2005; Ehrenberg, Ehrenberg, Smith, \& Zhang, 2004; Meredith, 2009; Shober, 2011; Silverman, 2011). In the present study, we focus on district bond elections, but a brief overview of the budget referenda literature helps to contextualize this research domain, focusing on the issues of refloating failed attempts and district and community factors.

First, for the issue of refloats, in examining a dataset of 1,919 budget referenda including California, Colorado and Minnesota from 2001-2005, Schober (2011) found that the total number of ballot measures within a district over the timespan was negative and significant on budget election outcome while in a study of 4,560 New York budget referenda from 1975-1997 Ehrenberg et al. (2004) found that failed budgets in one year had a lower chance of passing in the following year. However, neither of these studies addressed the conditional and dependent nature of the refloat data as discussed above. Second, as with the school bond literature, district and community factors also appear to play a role in district budget election outcomes. Silverman (2011) examined the percentage of the "no" vote for 179 New York budget referenda from 2003-2010 and found that larger districts had lower percentages of no votes, while districts with higher minority populations and a proposed change in spending had higher percentages of no votes. Furthermore, Ehrenberg et al. (2004) and Shober (2011) showed that suburban districts had lower chances of passing budget referenda, while districts had higher chances of passing a finance ballot measure with increasing enrollment in magnet and charter schools, long-term school boards and higher percentages of minority students, students in poverty, population over age 65 , and population with college degrees. In these ways, the broader district budget referenda literature provides additional context to help inform the more specific models of the factors most associated with passing capital facility finance bonds of the present study.

\section{Rationale of the Present Study}

While the recent research in the bond domain has helped to expand the earlier model proposed by Piele and Hall (1973), there are significant limitations to the studies. First is that the facility bond studies have been almost exclusively focused on Michigan while the budget election studies have overly focused on New York and California. While continued study of individual states helps to build and test a rich set of models, context-specific effects are problematic, as exemplified by the inclusion of technology in the bond wording, which was significant in Oklahoma but was unrelated to the models for Michigan bonds. In the dual effort to build both generalizable theory as well as widely applicable recommendations, there is a need in the literature to study these models and effects in other state contexts. Likewise, the variance explained across the bond election models has been relatively low, with the studies either not reporting an $\mathrm{R}^{2}$ statistic (Sielke, 1998; Zimmer \& Jones, 2005), as an indication of the amount of variance explained by the model in the probability of passing a bond, or reporting variance explained in the models as low as $11.2 \%$ (Bowers, et al., 2010a) 12.9\% (Beckham \& Maiden, 2003) $17.6 \%$ (Zimmer, et al., 2011), and as high as $24.6 \%$ (Bowers, et al., $2010 \mathrm{~b})$. This indicates that as the models and samples have improved, this research literature has been able to account for an increasingly large amount of the variance in the probability of passing school facilities bonds. However, while to date explaining only $25 \%$ of the variance from a single state is informative, in the attempt to build theory and practical recommendations, further work is needed to refine the models and test them in other contexts.

Second, the research domain lacks a strong theoretical model. Each study included above presents different overlapping sets of factors associated with bond passage or not, but researchers and especially school administrators looking for strategies to pass their bonds currently lack a theoretical framework from which to understand why and how some bonds pass while others fail. In noting this lack of recent theory on bond passage, while here we take the bond as the unit of analysis, we do not wish to discount the large body of work on the median voter model (Fort, 1988; Fort \& Bunn, 1998), especially as it applies to local school bond elections. As an example, Ladd's (1975) foundational work in this area demonstrated that "tax price" was significantly related to individual voter preferences for school construction debt. Ladd found that communities that relied more on a non-residential local tax base (measured as the percentage of the residential assessed value in the community) had stronger support for financing schools since it appeared that the residents off-loaded the costs onto local businesses (Ladd, 1975). However, our focus in the present study is on the bond as the unit of analysis, rather than on the median voter.

When taking the bond as the unit of analysis, since Piele \& Hall (1973), little work has been done to articulate a theory to contextualize the empirical findings across the studies. From the perspective of the theory postulated by Piele \& Hall (1973), they saw three types of characteristics around factors associated with the probability of bond passage that differed in the amount of influence a district administrator could exert on that factor. First, community characteristics such as district locale, enrollment, and demographics were viewed as constants. This in-turn influenced overall community support attitudes and voter preferences in ways that the administrator has little control over. Second, bond characteristics, such as wording and amount, were seen as somewhat malleable since while administrators may have a list of what is needed and how much that may cost, they have at least partial control over exact wording and amounts. According to Piele \& Hall (1973), they postulate that community demographics set the level of school support, but that bond characteristics may help drive overall voter participation. Third, election characteristics, such as the election date as well as a community's past voting history and tax base may influence participation. In addition, administrators may have some choice over aspects of election characteristics, such as the election date, which could influence the overall outcome. Thus, overall, while dated, Piele \& Hall's theory provides a starting point to begin to update these models.

Therefore, given the current lack of evidence demonstrating which factors associated with bond passage generalize across state contexts and multiple years of data, as well as the current lack of generalizable theory in the research to date, our strategy in the present study is to first examine which factors replicate and extend the findings from the past literature across state contexts using a direct effects model, focusing here on Texas using the longest time span to date, 1997-2009. We then move to re-examining the theory from Piele \& Hall (1973), informing the model using our findings and the findings across the studies to date in which we postulate a mediated model of school bond passage, helping to inform not only future research, but to aid administrators as they face important decisions as they ask their communities for needed funds through local election bond proposals. 
Consequently, the research questions for this study were:

1) To what extent do the previous models of school district bond passage apply in a different but recent state context, namely Texas from 1997-2008?

2) How does a model of bond passage rates from Texas inform both a) a theory of school district bond passage as well as b) recommendations for best practice to help schools pass elections to finance construction of needed school facilities?

\section{METHODS:}

\section{Sample}

This study analyzed all public school district capital facility finance bonds in Texas from 1997 through 2009. An analysis of Texas provides an interesting southern state context that has not previously been included in school bond election research, and due to the breathe of data available, also provides a unique opportunity to examine a large comprehensive longitudinal dataset of local school bond elections. Analyzing the entire population of data from a specific policy domain is recommended given the accessibility of the data, and the elimination of sample bias (Bowers, 2010). Additionally, the Texas context is important, in that unlike states such as Ohio and New York, Texas facility financing is similar to Michigan in that bond elections focus specifically on facilities, rather than including other district related budget items along with facilities. Thus, Texas provides an interesting policy domain to study, due to this similarity in facility finance policy across the states, along with the opportunity to examine bond passage rates in a large and demographically complex state, especially given our desire to test for the effects of demographics and district context on bond passage noted above. For a review of the differences and similarities in school finance policy across the states, especially as it relates to facilities financing, please see Sielke et al. (2001).

Publically accessible data was obtained from the Texas Bond Review Board (TBRB, n.d.) Texas ISD Bond Database, which includes information about all school district finance bonds in Texas including the district name, county, year, election date, proposition number, whether or not the bond carried or was defeated, amount of the bond and the purpose. The district names and counties were cross-referenced with the National Center for Education Statistics (NCES) Common Core of Data (CCD) (NCES, n.d.) to obtain the unique NCES district identification numbers. These ID numbers were then used to merge the Texas bond database with yearly reported district variables in the CCD, including district and community characteristics such as district locale (city, suburb, town, rural), and district enrollment among others. In addition, we used the Texas school district IDs to merge the Texas Education Agency's (TEA) Academic Excellence Indicator System (AEIS) database to include the local percent tax rate per district as a measure of tax burden in the school district, as well as the local tax price through including the percent residential assessed value (TEA, n.d.). Five bond proposals were excluded from the dataset due to incomplete or missing data. This resulted in a database with $n=2,224$ school district bond proposals covering the years 1997 through 2009, the largest school bond database analyzed to date. In addition, while NCES had not yet published finance data for districts for 2010 and 2011 at the time that this study was conducted, and thus the final statistical models had to be constrained to only the years 1997-2009 with complete data, the
Texas ISD Bond Database did report bond election results through 2011, and so we do provide some descriptive analysis of this data from 1997-2011, $n=2,469$.

\section{Variables Included in the Analysis}

We used previous theory, literature and the availability of relevant variables to guide our selection of variables for subsequent analysis. The means, standard deviations, minimum and maximums for variables included in the analysis are presented in Table 1. The dependent variable for the study was if a school district bond election passed or failed. The independent variables are separated into five categories that represent the main themes from the literature and were available in the public datasets. First, bond characteristics include float and the bond amount, in millions of dollars. Following and expanding upon the recommendations from the previous literature on multiple school district bond attempts (Bowers, et al., 2010a, 2010b), we examined the data and found that it appeared that school districts that had a bond fail, would "refloat" the bond for a substantively similar amount and purpose within 36 months of the original election. Hence, we defined the first attempt as a first float, the second attempt as a second float, and a few districts attempted a third float. In addition, some districts along with refloating a bond broke up a larger past failed bond into smaller bonds upon the second or third float. These were also coded as a second or third float. The purpose listed for each bond was coded into seven categories, building (reference group), renovations, debt refinance, athletics facilities, technology, art, and other. The other category included "no-report" as well as all other purposes listed in the database such as for land purchase and transportation among others. District locale was coded following the recommendations of the NCES for coding the reported metro-centric and urban-centric CCD locale codes into city, suburb, town and rural (reference group) and enrollment, in thousands, for each district for each year was also included. Since many districts propose bonds to build new facilities due to enrollment growth, we wished to include a measure to capture this variance. To include a measure of enrollment growth, we first calculated percentage enrollment change year-to-year. To capture a district's general annual trend in enrollment over the thirteen years, growth/decline/neutral, we then fit a regression line to the percent change year to year and included the unstandardized regression coefficient as the average annual percentage change in enrollment. Community characteristic variables included two types. First, following past research (Ehrenberg, et al., 2004; Shober, 2011), year 2000 census data was included for each district for the percentage of the population over age 65, as well as the percentage of the population with a college degree (either 2-year or 4-year). Second, student demographic variables for each district for each year were included from the $\mathrm{CCD}$, including percent free lunch, Native American, Asian, African American, and Hispanic students. Election characteristics included the tax rate, the percentage of the residential assessed value, if the election occurred after July 1 in the calendar year in which it was proposed, and the location of the bond on the ballot on election day as either proposition issue \#2, issue \#3, or issue \#4 or more, with issue \#1 and "no report" combined as the reference group. We included election occurred after July 1 since previous to 2006, districts could schedule special elections in Texas on a variety of dates throughout the calendar year, however since 2006 districts were required to hold the election in either May or November. Thus, to examine the past findings of time of year in the model, we dichotomized election date. 
Table 1: Descriptives for variables included in the model

\begin{tabular}{lrrrc}
\hline & Mean & \multicolumn{1}{c}{ SD } & Min & Max \\
\hline & & & & \\
Bond Election Passed (dependent variable) & 0.77 & 0.42 & 0 & 1 \\
Bond Characteristics & & & & \\
First Float & 0.90 & 0.30 & 0 & 1 \\
Second Float & 0.09 & 0.29 & 0 & 1 \\
Third Float & 0.01 & 0.11 & 0 & 1 \\
Bond Amount (in millions) & 38.07 & 90.69 & 0.10 & 1366.30 \\
Bond Wording & & & & \\
Renovations & 0.12 & 0.32 & 0 & 1 \\
Debt Refinance & 0.03 & 0.17 & 0 & 1 \\
Athletics & 0.07 & 0.25 & 0 & 1 \\
Technology & 0.02 & 0.12 & 0 & 1 \\
Art & 0.01 & 0.09 & 0 & 1 \\
Other & 0.29 & 0.45 & 0 & 1 \\
District Characteristics & & & & \\
City & 0.14 & 0.35 & 0 & 1 \\
Suburb & 0.28 & 0.45 & 0 & 1 \\
Town & 0.17 & 0.37 & 0 & 1 \\
Enrollment (in thousands) & 7.53 & 15.50 & 0.04 & 210.99 \\
\% Average Annual Change in Enrollment & 0.18 & 0.37 & -6.39 & 1.83 \\
Community Characteristics & & & & \\
\% Population over age 65 & 11.96 & 5.01 & 2.27 & 31.98 \\
\% Population with a college degree & 14.81 & 8.18 & 1.86 & 92.93 \\
\% Free lunch students & 34.02 & 17.87 & 0 & 95.73 \\
\% Native American students & 0.40 & 0.82 & 0 & 26.39 \\
\% Asian Students & 1.27 & 2.47 & 0 & 24.58 \\
\% African American students & 9.09 & 12.44 & 0 & 86.07 \\
\% Hispanic students & 31.03 & 27.68 & 0 & 99.91 \\
Election Characteristics & & & & \\
Tax Rate & 1.49 & 0.17 & 0.70 & 2.00 \\
\% Residential Assessed Value & 42.91 & 21.01 & 0 & 94.40 \\
Election occurs after July 1 & 0.45 & 0.50 & 0 & 1 \\
Bond is issue \#2 on ballot & 0.14 & 0.34 & 0 & 1 \\
Bond is issue \#3 on ballot & 0.06 & 0.23 & 0 & 1 \\
Bond is issue \#4 or more on ballot & 0.03 & 0.17 & 0 & 1 \\
\hline & & & &
\end{tabular}

Analytic Model

Following the recommendations of the previous literature on modeling the conditional nature of the data on bond floats and refloats (Bowers, et al., 2010a, 2010b) we used discrete-time hazard modeling (Singer \& Willett, 2003) to estimate the probability of a bond passing or failing in Texas between 19972009. The data are conditional because a bond is not eligible to be a refloat unless it has failed on the previous attempt, and no bonds that passed on the first attempt can be second floats. For a review of conditional dataset analysis and discrete-time hazard modeling see Singer and Willet (2003). Briefly, we constructed the dataset as a unit-period dataset, such that rather than list each district once, the bond was considered the unit of analysis, so each row of the dataset represents each attempt of a bond. This allows the probability of passing the bond to be appropriately estimated given the conditional nature of the data, such that each float is considered 
Table 2: Texas school district bonds 1997-2009, by bond wording, district locale and floats.

\begin{tabular}{|c|c|c|c|c|c|c|c|c|}
\hline & \multicolumn{2}{|c|}{ First Float } & \multicolumn{2}{|c|}{ Second Float } & \multicolumn{2}{|c|}{ Third Float } & \multicolumn{2}{|c|}{ All Floats } \\
\hline & Total & $\%$ Pass & Total & $\%$ Pass & Total & $\%$ Pass & Total & $\%$ Pass \\
\hline \multicolumn{9}{|l|}{ Bond Wording } \\
\hline Buildings & 1161 & 78.21 & 123 & 74.80 & 14 & 57.14 & 1298 & 77.66 \\
\hline Renovations & 236 & 81.78 & 23 & 78.26 & 3 & 100.00 & 262 & 81.68 \\
\hline Debt Refinance & 60 & 81.67 & 4 & 100.00 & 25 & 44.00 & 64 & 82.81 \\
\hline Athletics & 124 & 62.90 & 19 & 63.16 & 3 & 33.33 & 146 & 62.33 \\
\hline Technology & 32 & 84.38 & 3 & 66.67 & 25 & 44.00 & 35 & 82.86 \\
\hline Art & 17 & 58.82 & 1 & 100.00 & 25 & 44.00 & 18 & 61.11 \\
\hline Other & 572 & 81.64 & 45 & 68.89 & 6 & --- & 623 & 79.94 \\
\hline \multicolumn{9}{|l|}{ District Locale } \\
\hline City & 279 & 79.21 & 22 & 72.73 & 1 & 100.00 & 302 & 78.81 \\
\hline Suburb & 567 & 80.25 & 50 & 80.00 & 14 & 35.71 & 631 & 79.24 \\
\hline Town & 325 & 73.23 & 39 & 64.10 & 3 & 33.33 & 367 & 71.93 \\
\hline Rural & 828 & 78.50 & 89 & 71.91 & 7 & 57.14 & 924 & 77.71 \\
\hline All Bonds & 1999 & 78.24 & 200 & 72.50 & 25 & 44.00 & 2224 & 77.34 \\
\hline
\end{tabular}

Note: Bond wording categories can sum to greater than $100 \%$ due to overlapping categories

a pseudo-intercept in a logistic regression equation, taking the general form of:

$$
\begin{gathered}
\operatorname{logit}(Y)=\alpha_{\text {First float }} X_{\text {First float }}+\alpha_{\text {Second float }} X_{\text {Second float }}+\alpha_{\text {Third float }} X_{\text {Third float }}+\beta_{1} X_{1} \\
+\beta_{2} X_{2}
\end{gathered}
$$

In which, the dependent variable is modeled as the logit of passing a bond, the three pseudo-intercepts are represented for each float by a separate alpha, then each predictor is included with its own beta as in a regular logistic or multiple regression. Because logit regression coefficients are inherently difficult to interpret, we converted significant coefficients into odds $\left(\mathrm{e}^{\wedge}(\right.$ logit $\left.)\right)$ as recommend (Borooah, 2002; Singer \& Willett, 2003).

\section{RESULTS}

In comparison to school bond passage rates in the other recent studies discussed above, the Texas bond passage rate from 19972009 was high, at $77 \%$ (see Table 1), indicating that over this thirteen-year time-span the more likely outcome has been bond passage. However, the purpose of this study is to assess the extent to which specific variables nominated in past research in other states are associated with bond passage rates in Texas, controlling for other variables in the model, to inform both theory and practice. Table 2 disaggregates the frequencies for school district bond passage rates by float, bond wording and district locale for $n=2,224$ bonds. As discussed in the methods, a first float is defined as the first attempt by a district to pass a bond, where the second and third float is defined as "refloating" substantially similar bonds if the first attempt failed. For Texas from 1997-2009, 90\% of the bonds were first floats with $78.24 \%$ passing, $9 \%$ were second floats with $72.50 \%$ passing, and $0.11 \%$ were third floats with $44.00 \%$ passing (Table 2, bottom row). In addition, there appear to be interesting differences when examining bond pass rates by the wording of the purpose of the bond as well as district locale (Table 2 , far right column). Bonds requesting school facility renovations or refinancing of district debt appear to pass more often than other types of bonds, while bonds for athletics (such as stadiums and fields) or art (such as performance halls or auditoriums) pass much less often than their counterparts. Interestingly though, all passage rates were over $50 \%$. Examining bond passage rates by district locale, as opposed to the Michigan studies, while towns had somewhat lower passage rates than other districts, all districts passed about three-quarters of their bonds. Also, as a departure from past studies, when disaggregating the data by float and wording or locale, there appeared to be few differences that were not reflected in the total numbers. However, while descriptives such as those presented in Tables 1 and 2 provide an overview of the data, we turn next to the question of which variables are significant in an overall model of bond passage in Texas when controlling for the other variables of interest.

As noted in the methods, we used discrete-time hazard modeling to model the probability of passing a school district bond in Texas from 1997-2009. The baseline hazard model including only first float, second float and third float, is akin to an empty or unconditional model, and indicated a significant and decreasing probability of passing a bond on multiple attempts with decreasing odds ratios for first, second and third floats of 3.595, 2.636, and 0.786 respectively, with logit coefficients of $1.280,0.969$, and 0.241 . Much like in multiple and hierarchical linear regression, where the unconditional intercept (constant) represents the mean outcome for the entire sample, here the baseline hazard model represents the overall probability at each time point (float) of passing the bond, such that converting the baseline coefficients into fitted hazard probabilities $\left(1 /\left(1+\mathrm{e}^{\wedge}(-\operatorname{logit})\right)\right)$ equals 0.782 , 0.725 and 0.440 for the first, second and third floats, which match exactly to the basic frequencies reported for the pass rates in the bottom row of Table 2. This demonstrates the effect size of the decrease in the probability of passing a bond when it is refloated, in that the decrease experienced between first and second floats was only $5.7 \%$, while there was a $34.2 \%$ difference in passage probability between first and third floats in the unconditional model. The fit statistics for the baseline hazard model $-2 \log$ likelihood equaled 2363.975 with pseudo $\mathrm{R}^{2}$ of 0.276 for the Cox and Snell estimate and 0.368 for Nagelkerke. Because there is no direct method to calculate the variance explained in a logistic regression (Borooah, 2002), providing two estimates of the variance explained, one conservative and one liberal, is recommended. Here, the variance explained estimates indicate that the unconditional model alone accounts for about 30\% of the variance in bond passage rates in Texas.

Table 3 presents a step-wise discrete-time hazard model estimating the probability of passing a school district bond election in Texas 
Table 3: Logistic regression model estimation of passing a Texas school district capital facilities finance bond, 1997-2009.

\begin{tabular}{|c|c|c|c|c|c|c|c|c|c|}
\hline & \multicolumn{3}{|c|}{ Model A } & \multicolumn{3}{|c|}{ Model B } & \multicolumn{3}{|c|}{ Model C } \\
\hline & Coeff. & $S E$ & $\begin{array}{l}\text { Odds } \\
\text { Ratio }\end{array}$ & Coeff. & $S E$ & $\begin{array}{l}\text { Odds } \\
\text { Ratio }\end{array}$ & Coeff. & $S E$ & $\begin{array}{c}\text { Odds } \\
\text { Ratio }\end{array}$ \\
\hline \multicolumn{10}{|l|}{ Bond Characteristics } \\
\hline First Float & $1.173^{* * *}$ & 0.117 & 3.232 & $1.598^{* *}$ & 0.603 & 4.945 & $2.344^{* *}$ & 0.760 & 10.425 \\
\hline Second Float & $0.897 * * *$ & 0.190 & 2.453 & $1.426^{*}$ & 0.627 & 4.160 & $2.205^{* *}$ & 0.773 & 9.067 \\
\hline Third Float & -0.324 & 0.422 & & 0.274 & 0.748 & & 0.910 & 0.886 & \\
\hline Bond amount (in millions $\$)^{\mathrm{a}}$ & 0.027 & 0.035 & & $-0.241^{* * *}$ & 0.065 & 0.786 & $-0.245^{* * *}$ & 0.069 & 0.783 \\
\hline Renovations & 0.305 & 0.173 & & 0.335 & 0.178 & 1.398 & $0.497 * *$ & 0.184 & 1.644 \\
\hline Debt Refinance & 0.410 & 0.345 & & 0.494 & 0.367 & & 0.633 & 0.371 & 1.883 \\
\hline Athletics & $-0.671^{* * *}$ & 0.188 & 0.511 & -0.362 & 0.213 & 0.696 & -0.326 & 0.219 & \\
\hline Technology & 0.286 & 0.454 & & 0.373 & 0.473 & & 0.553 & 0.479 & \\
\hline Art & -0.753 & 0.490 & & -0.285 & 0.520 & & -0.338 & 0.531 & \\
\hline Other & 0.189 & 0.124 & & 0.160 & 0.139 & & -0.203 & 0.219 & \\
\hline \multicolumn{10}{|l|}{ District \& Community Characteristics } \\
\hline City & & & & 0.029 & 0.247 & & -0.006 & 0.254 & \\
\hline Suburb & & & & 0.048 & 0.168 & & -0.039 & 0.174 & \\
\hline Town & & & & -0.157 & 0.168 & & -0.194 & 0.171 & \\
\hline Enrollment (in thousands) ${ }^{\mathrm{a}}$ & & & & 0.019 & 0.090 & & -0.050 & 0.093 & \\
\hline$\%$ Avg. change annual enrollment & & & & $0.440^{*}$ & 0.191 & 1.552 & $0.497^{*}$ & 0.194 & 1.643 \\
\hline$\%$ Pop over age 65 & & & & $-0.041^{* *}$ & 0.015 & 0.960 & $-0.044^{* *}$ & 0.015 & 0.957 \\
\hline$\%$ Pop with a college degree & & & & 0.004 & 0.009 & & 0.003 & 0.010 & \\
\hline$\%$ Free lunch students & & & & 0.001 & 0.005 & & 0.001 & 0.005 & \\
\hline$\%$ Native American students & & & & -0.081 & 0.059 & & -0.091 & 0.058 & \\
\hline$\%$ Asian students & & & & $0.120^{k *}$ & 0.038 & 1.127 & $0.127^{* * *}$ & 0.039 & 1.135 \\
\hline$\%$ African American students & & & & -0.003 & 0.005 & & -0.003 & 0.006 & \\
\hline$\%$ Hispanic students & & & & $0.008^{* *}$ & 0.003 & 1.008 & $0.008^{* *}$ & 0.003 & 1.008 \\
\hline \multicolumn{10}{|l|}{ Election Characteristics } \\
\hline$\%$ Tax rate & & & & 0.341 & 0.328 & & -0.432 & 0.511 & \\
\hline$\%$ Residential assessed value & & & & -0.003 & 0.004 & & -0.003 & 0.004 & \\
\hline Election after July 1 & & & & 0.116 & 0.110 & & 0.117 & 0.113 & \\
\hline Proposition \#2 & & & & $-0.907 * * *$ & 0.184 & 0.404 & $-0.880^{* * * *}$ & 0.189 & 0.415 \\
\hline Proposition \#3 & & & & $-1.178^{* * *}$ & 0.251 & 0.308 & $-1.132 * * *$ & 0.259 & 0.322 \\
\hline Proposition \#4 or greater & & & & $-1.786^{* * *}$ & 0.317 & 0.168 & $-1.743 * * *$ & 0.328 & 0.175 \\
\hline \multicolumn{10}{|l|}{ Election Year (ref. 2009) } \\
\hline 1997 & & & & & & & $0.827^{*}$ & 0.379 & 2.286 \\
\hline 1998 & & & & & & & $0.761 \sim$ & 0.402 & 2.140 \\
\hline 1999 & & & & & & & $1.194 * *$ & 0.409 & 3.300 \\
\hline 2000 & & & & & & & 0.494 & 0.348 & \\
\hline 2001 & & & & & & & $0.847^{*}$ & 0.365 & 2.333 \\
\hline 2002 & & & & & & & 0.260 & 0.347 & \\
\hline 2003 & & & & & & & 0.139 & 0.358 & \\
\hline 2004 & & & & & & & 0.443 & 0.366 & \\
\hline 2005 & & & & & & & 0.225 & 0.370 & \\
\hline 2006 & & & & & & & $0.601 \sim$ & 0.364 & \\
\hline 2007 & & & & & & & $1.063^{* *}$ & 0.339 & 2.895 \\
\hline 2008 & & & & & & & -0.134 & 0.303 & \\
\hline \multicolumn{10}{|l|}{ Goodness-of-fit } \\
\hline -2 Log Likelihood & 2337.842 & & & 2222.768 & & & 2185.338 & & \\
\hline Cox and Snell $\mathrm{R}^{2}$ & 0.285 & & & 0.321 & & & 0.332 & & \\
\hline Nagelkerke $\mathrm{R}^{2}$ & 0.380 & & & 0.428 & & & 0.443 & & \\
\hline
\end{tabular}

$\sim p \leq 0.01,{ }^{*} p \leq 0.05,{ }^{* *} p \leq 0.01,{ }^{* * *} p \leq 0.001 ;{ }^{\mathrm{a}}$ indicates the variable was natural log transformed

between 1997 and 2009 (see methods). While logistic regression is robust under non-normal data conditions (Borooah, 2002) the variables bond amount and enrollment were natural log transformed as recommended in such cases to correct for extreme skewness in the data which helps to provide more accurate parameter estimates and standard errors. Model A examines the effects of bond characteristics on the outcome of the probability of passing a bond, and includes float as well as bond amount and bond wording. Model A accounts for about one third of the variance in the likelihood of passing a bond. Model B adds district and community characteristics as well as election characteristics to the model, explaining between $32.1 \%$ and $42.8 \%$ of the variance in the probability of passing a bond. Model $\mathrm{C}$ adds each of the years from 1997 to 2009 to control for variance in year-to-year fluctuations of community support for school bond elections, with 2009 as the reference group (see Table 3). 
Table 4: Texas facilities bond percent pass and mean, standard deviation, sum, minimum and maximum for bond amounts per year (in millions of \$).

\begin{tabular}{rrrrrrrr}
\hline & Number & \% Pass & Mean & \multicolumn{1}{c}{ SD } & \multicolumn{1}{c}{ Sum } & Min & \multicolumn{1}{c}{ Max } \\
\hline 1997 & 218 & 81.65 & 15.618 & 38.389 & $3,404.825$ & 0.125 & 483.475 \\
1998 & 126 & 78.57 & 33.260 & 76.276 & $4,190.820$ & 0.355 & 678.000 \\
1999 & 180 & 86.67 & 29.168 & 55.250 & $5,250.275$ & 0.230 & 398.000 \\
2000 & 166 & 78.31 & 27.564 & 60.483 & $4,575.645$ & 0.500 & 398.000 \\
2001 & 163 & 81.59 & 30.052 & 70.152 & $4,898.462$ & 0.325 & 495.000 \\
2002 & 184 & 72.28 & 40.685 & 128.900 & $7,486.056$ & 0.173 & $1,366.295$ \\
2003 & 161 & 70.19 & 37.514 & 79.385 & $6,039.771$ & 0.100 & 478.000 \\
2004 & 175 & 77.14 & 43.394 & 80.221 & $7,593.878$ & 0.300 & 659.100 \\
2005 & 149 & 73.15 & 40.926 & 63.600 & $6,097.967$ & 0.240 & 399.000 \\
2006 & 207 & 77.78 & 38.020 & 75.374 & $7,870.213$ & 0.175 & 798.000 \\
2007 & 233 & 81.97 & 62.974 & 137.100 & $14,673.025$ & 0.500 & 807.000 \\
2008 & 168 & 67.86 & 60.295 & 143.800 & $10,129.577$ & 0.400 & $1,350.000$ \\
\hline 2009 & 95 & 70.53 & 25.959 & 36.687 & $2,466.065$ & 0.230 & 197.500 \\
2010 & 131 & 48.85 & 34.973 & 78.527 & $4,581.413$ & 0.620 & 535.142 \\
2011 & 108 & 64.81 & 36.605 & 66.492 & $3,953.308$ & 0.310 & 399.410 \\
\hline Totals & 2,469 & 75.25 & 37.829 & 89.101 & $93,211.301$ & 0.100 & $1,366.295$ \\
\hline
\end{tabular}

As the final full model in Table 3, Model $\mathrm{C}$ explains between $33.2 \%$ and $44.3 \%$ of the variance in the likelihood of passing a school bond election in Texas between 1997 and 2009. This is the largest reported variance explained to date in this research domain. Significant parameter estimates in the model include first and second float, with third float non-significant most likely due to the low proportion of bonds that were third floats, which is in turn most likely due to the overall high probability of all bonds passing, leaving few to persist to third float in Texas. For bond characteristics, bond amount was negative and significant in the model, and we show for the first time in the recent school bond research that bonds including wording for renovations and debt refinancing were significantly more likely to pass, controlling for the other variables in the model. Interestingly, while athletics was significantly negative in Model A, upon inclusion of district and community as well as election characteristics, the fact that athletics is no longer significant in Models B and C indicates that these models now explain that variance. In testing an intermediate model which did not include election characteristics, athletics was still significant and negative (data not shown), suggesting that it is the election characteristics that are explaining the variance in the negative effect of athletics on bond passage rates. Interestingly, for district and community characteristics, district locale was not significant in the final full model, nor was enrollment, percentage of population with a college degree, or percent free lunch students, which differs from the findings from Michigan. Average percentage annual change in enrollment was positive and significant, which most likely reflects that many districts in Texas request new facilities due to enrollment growth. However, percent population age 65 or over was strongly negatively significant controlling for the other variables in the model. Furthermore, for the first time in the recent literature, percent of students from different ethnic groups was tested in the model as a proxy for the community demographics, and indicated percentage of Asian and
Hispanic students had a significant and positive relationship with passing a school bond.

For election characteristics, only the proposition number was significant and strongly negative in the final models. As an indication of the position on the ballot, each successive lower placement down the ballot experienced increased negative odds of passage, with bonds that were in position four or lower being 5.71 times less likely to pass than bonds that were in the reference group (converting odds of passing into odds of not passing to interpret an odds ratio less than 1.0 gives odds $^{-1}=0.175^{-1}=5.71$ ) controlling for the other variables in the model (see Table 3). Additionally, Model $\mathrm{C}$ includes year, controlling for the variance in passage rates due to yearly exogenous fluctuations in community bond election preferences. In comparison to 2009 as the reference group, all years analyzed had higher likelihoods of having a bond passed except for 2008, with 1997-1999, and 2001 and 2007 significantly higher.

While the models described here only include data from 1997 to 2009 , due to the need for complete data across the district and community variables (see methods), the state of Texas did report the outcomes for bonds in 2009-2011. Table 4 presents descriptive statistics for the entire available fifteen year dataset, including per year the number of bonds proposed, passage rates, mean amount in millions of dollars, standard deviation, total amount of bond requests per year, and the minimum and maximum each year. Examining Table 4 reveals that bond passage rates for the state fluctuated between $70.19 \%$ as a low in 2003 and $86.67 \%$ as a high in 1999 until 2008, in which passage rates dipped below $70 \%$ for the first time in the dataset. The 2008 decline coincides with the onset of the 2008 U.S. nation-wide recession, which has been widely reported as the worst U.S. economic down-turn since the great depression in the 1930s (Temin, 2010), and corresponds to 
the tightening of the municipal bond debt market at the time. Indeed, the subsequent years of 2009-2011 appear to have been a radically different context in which to attempt to pass a bond, with overall numbers of bonds proposed in 2009 at only 95, 40.7\% of the high of 233 proposed bonds just two years earlier in 2007 (see Table 4). In addition, overall bond amounts drastically declined, and for the first time in the dataset in 2010, less than two-thirds of the bonds in the state passed, with the passage rate dipping below $50 \%$, and only $64.81 \%$ of bonds passing in 2011 .

\section{DISCUSSION}

The purpose of this study was to examine the factors most associated with passing or failing school district bond elections in Texas. The Texas model provides a useful comparison to the past literature as well as a comparison to the more recent research including Michigan and Oklahoma. We divide the following discussion into three sections. First, we discuss the results as they relate to informing the theory around school bond elections. Second we discuss the limitations of the study, and then we conclude with specific recommendations aimed at informing school district administrator practice with recommendations that generalize across state contexts as well as what may be more specific for Texas.

Past models of bond passage put forward by Piele and Hall (1973) indicated that there are two broad and competing effects on the likelihood of passing a bond. First is the overall community support for voting for new taxes to support school construction and construction debt financing. According to the theory, community support is mostly constant on yearly timescales, changing only at a more glacial pace as demographics change over generations. This is predicted since the majority of voter behavior is highly related to community demographics, such as the age, education and SES of the local population. Consequently, each community appears to have a consistent fraction of "yes" voters, and according to Piele and Hall (1973), bond elections seem to turn on getting these voters to the polls, especially in communities in which overall support for school bond elections is weak. The second effect which competes with the first however is that while the administration has quite a bit of control over election timing, bond size and wording, according to Piele and Hall (1973), almost none of these aspects of the bonds in their studies were significantly related to passage, with the overall community preferences dominating the past models. However, the more recent work reviewed above takes the bond as the unit of analysis, and analyzes much larger and complete state-wide datasets over multiple years using more appropriate statistics, methods and samples that were not available in the 1970s. This more recent work has identified bond and election characteristics that can be tailored by the school administration, that while the district must acknowledge the old adage that "all politics is local" (Berkman \& Plutzer, 2005; Price, 1932), and that they may have a consistent fraction of yes voters, there are specific aspects of a bond that appear to be favored over others. In our model, this included the community characteristics as well as bond and election characteristics.

In the following section, we discuss our findings as they relate to this issue of studying the bond as the unit of analysis and this difference between community characteristics that are outside the influence of district administrators versus bond and election characteristics that appear to be malleable by the district and thus can vary over time and impact the probability of a bond passing. After discussing each of the main types of community, bond and election characteristics, we then offer a combined framework to help guide future research and theory building through a possible mediated model that could be tested using Structural Equation Modeling (SEM).

\section{Community Characteristics}

In the present study, we found that controlling for the other variables in the model, district locale as well as enrollment was not significantly associated with the probability of passing a school bond, but that growth in enrollment was positive and significant. While district size, as measured by enrollment, has been shown previously to not be related to bond passage rates (Bowers, et al., 2010b; Piele \& Hall, 1973; Zimmer, et al., 2011) and so the nonsignificant finding here is consistent with the past research, the non-significance of district locale was unexpected given the past research from Michigan that showed that small towns and rural districts are at an increased disadvantage in attempting to pass a bond (Bowers, et al., 2010a, 2010b; Zimmer, et al., 2011; Zimmer $\&$ Jones, 2005). Our findings here suggest that district locale may be context specific, and that it may matter more in states such as Michigan than in states such as Texas. We encourage future research to continue to explore this issue.

Furthermore, we found that controlling for the other variables in the model, the percent of the population over age 65 was negative and significant on the probability of passing a bond, while the percentage of the population with a college degree and the percentage of free lunch students were not significant in the model. The negative finding of percentage of the population over age 65 is consistent with previous literature, in that not only can the senior citizen population be active in voting in most communities, but that they are traditionally seen as relatively unsupportive of new school debt (Button \& Rosenbaum, 1989; Duncombe, et al., 2003; Piele \& Hall, 1973), due in part to decreased incomes brought on by retirement as well as not having children currently enrolled in the local schools. However, recent work in the broader school budget referenda literature suggests that population over age 65 is positive on school finance measures in New York (Ehrenberg, et al., 2004), Florida (Duncombe, et al., 2003), California, Colorado and Minnesota (Shober, 2011), and thus the traditional idea of the retiree as unsupportive of increased school taxes may be suspect (Berkman \& Plutzer, 2005). Our findings suggest either a context effect specific for Texas or a difference between favoring increased school revenue but perhaps not facilities.

In contrast with our finding on percent of population over age 65 , percent of the population with a college degree and percent of free lunch students, as a proxy for the relative poverty in the community, were not significant. Poverty and education in a community as measured similar to the present study as well as with median income and percent in poverty, have been shown previously to be significantly related to bond passage rates (Bowers, et al., 2010b; Piele \& Hall, 1973; Zimmer, et al., 2011), however in Texas, controlling for the other variables in the model, these variables do not appear to be as important. However, as with percentage population over age 65 , the percentage of the population with a college degree is based on the data available for each district in the NCES Common Core of Data (CCD), the 2000 U.S. census data. These variables are changing over time, but we were limited to modeling them as time invariant due to the decennial data collection cycle in the U.S. In addition, while percent free lunch students varies with time in the model, percent free and reduced lunch would have been a more acceptable variable to model, however it was unavailable for 1997 and 1998 data in the CCD, so to include those two years of data we used 
percent free lunch as a reasonable proxy. Future research should work to include broader measures of community education and poverty in Texas to increase the accuracy of the model.

This study is the first in the more recent research to model the percentage of students from different ethnic groups attending the school district on the probability of passing a bond. According to Piele and Hall (1973), whites, while more likely to turnout for an election, were less likely to vote for school bonds, whereas nonwhites were more likely to vote in favor, as is also the finding from the broader school budget referenda literature (Ehrenberg, et al., 2004; Shober, 2011; Silverman, 2011). Here, we've replicated those findings in which higher proportions of Asian and Hispanic students corresponded to an increased likelihood of passing a bond, all else being equal. For Texas, this is an especially relevant finding given the large and growing Hispanic population, and that many cities in Texas have a majority of students who are Hispanic (Guzmán, 2001). Our model suggests that in Texas, the relatively rapidly shifting demographics present an opportunity for school districts, in that in comparison to communities which have stable demographics; these shifting demographics could be providing Texas districts an increase in the "yes" voter fraction of their communities. In addition, we postulate that the large and growing Hispanic population may contribute to the overall high rates of bond passage experienced in Texas. Future research should examine cross-state comparisons to address this issue. Furthermore, following recent research on education and the demographic changes in the U.S., especially in the south and southwest (Glass, 2008), we hypothesize that there may be a rising tension in Texas, as demonstrated by the dual results of the negative effect of older voters versus the positive effect of increased proportions of non-white students in schools which are both growing in Texas and may have opposite preferences for school bond issues. Future research should examine this issue as it may become more pronounced over time. While the recent 20092011 decline in bond amounts and passage rates in Texas are most likely explained by the recession, conflated with this are these significant demographic changes which may be impacting the traditionally strong support in Texas for school bonds.

\section{Bond Characteristics}

Our findings indicate that important bond characteristics include float, amount of the bond, and the bond purpose being related to renovations or debt refinancing, controlling for the other variables in the model. The point that refloats of bonds appear to have lower chances of success, replicates the recent findings from Michigan (Bowers, et al., 2010a, 2010b), indicating that the first float has the best chances of passing. In addition, few studies of school bond passage have analyzed the purpose of the bonds. We found that bonds requesting renovations were 1.644 times more likely to pass than bonds not requesting renovations, and bonds requesting refinancing were 1.883 times more likely to pass. For renovations, it may be that voters are more willing to pay for "upgrades" to facilities in comparison to other options; while for refinancing, districts usually promote the bond as "no new increase in taxes" as they refinance their existing debt for more years. What is usually not mentioned in these instances is that if the bond were to fail, that there would be a subsequent decrease in taxes. It may be that this strategy works, or equally plausible, Texas voters may support a "neutral" taxation policy, in which new taxes are not favored, but extending current taxes is seen as an acceptable way to fund needed facilities.
Interestingly, bond amount was significant in our model. On the surface, intuition suggests that voters may have "sticker shock", or at the least, large bonds indicate a large increase in taxes, which might be seen as a negative. The research from Michigan supports this point (Bowers, et al., 2010b), and we have replicated it here with Texas data. However, bond amount was not a significant predictor in the Oklahoma study (Beckham \& Maiden, 2003) and had mixed results in Piele and Hall (1973). This may indicate, all other variables being equal, that influence of bond amount on bond election outcomes may be state context specific. In addition, this point may be equally true for the other types of purposes for the bond, including technology, which was significant in Oklahoma (Beckham \& Maiden, 2003), but not in the present study for Texas. Our future research will work to further explore this issue.

\section{Election Characteristics}

An interesting recent finding from Michigan was that district longterm debt was significantly related to increasing rates of bond passage (Bowers, et al., 2010b; Zimmer, et al., 2011; Zimmer \& Jones, 2005) as was election day of the year and proposition number (Bowers, et al., 2010b), however previous research showed that district local property tax revenue was not significantly related to bond passage rates (Sielke, 1998). We tested similar models for the Texas data and found that the local tax rate (as a measure of the local tax burden), or if the election was in the second half of the year were each not significantly related to the likelihood of bond passage. It may be that the generally high rates of bond passage in Texas during this time swamp out the effect of property taxes and timing, since the vast majority of bonds pass. In addition, the variable percent residential assessed value, as a measure capturing the local tax price, was not significantly related to bond passage, further indicating that the bond as the unit of analysis diverges from the traditional median voter model of election behavior. Future research should continue to include these variables as predictors, since it appears that they may be context specific.

In contrast, in replication of the Michigan research (Bowers, et al., 2010b), proposition number was strongly negatively significant on the likelihood of passing a bond. Bond proposals that were the second, third, fourth or lower on the ballot were significantly less likely to pass, controlling for the other variables in the model. This finding supports the previous hypothesis of "voter fatigue", in that voters are more likely to vote for a school bond when it is at the top of the ballot, but that successive ballot measures are rejected at successively higher rates.

\section{A Proposed Mediated Model of School Bond Passage}

Here, to summarize our findings above in relation to the past research, and to provide a framework for future research to test a more comprehensive model of bond passage, we turn next to offering a proposed mediated model in an SEM framework. Our goal is to encourage future work in this area that addresses a more comprehensive mediated theory of facility bond passage. As with all of the other recent studies on school bond passage, we analyzed a direct effects model. While we argue here that our model is the most comprehensive to date, explaining the largest amount of variance in bond passage in the recent studies, we acknowledge that a direct effects model is insufficient to fully delineate a contemporary theory of school bond passage. This is because few of the variables included in any of the recent models have a direct impact on balloting at the polls, but rather must act through the communal action of a community as it either supports school bonds or not, which in turn most likely influences participation in elections, which then results in specific voters with a specific 


\section{Local Characteristics}

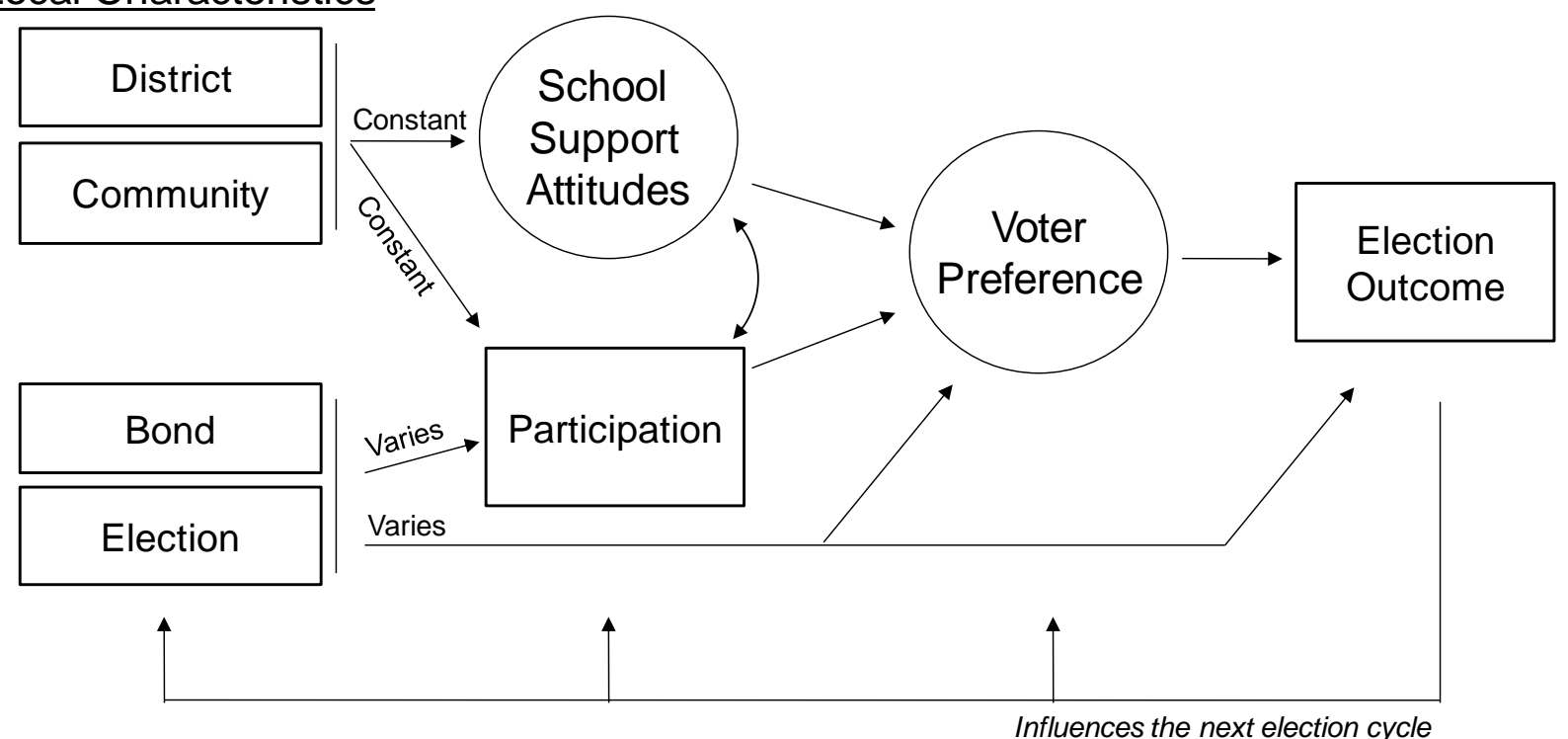

Figure 1: Proposed alternative mediated model of school bond passage

preference for the bond showing up on election day and actually voting. In combining our results here from our direct effects model with those of the past literature, as well as the theory proposed by Piele and Hall (1973), our results point to a new mediated model of school bond passage, which we propose here (see Figure 1).

Reading Figure 1 from left to right, we propose an expanded mediated model that could be tested through adapting a structural equation modeling framework to what is now known about these variables and how they may interact. As discussed above, Piele and Hall (1973) noted that in the studies they reviewed it appeared that most of the variables that were significantly associated with school bond passage or failure were constant across a community, such as aspects of the district and community, and that these local characteristics directly influenced both the overall community school support attitudes as well as participation in school bond elections (Figure 1, top left). Conversely, the recent direct effects models, including the results reported here, indicate that there are significant malleable factors in a bond election that are under the control of school district administrators, including bond and election specific variables, such as bond size, wording, and the position of the bond on the ballot (Figure 1, bottom left). Synthesizing both the past and recent research, it appears that while district and community characteristics may consistently influence school support attitudes and participation, and that community-wide school support attitudes remain mostly constant and beyond the influence of school administrators, the varying aspects of bond and election characteristics may directly influence participation and voter preferences, which then, through voter preferences, act on the election outcome. One can also imagine specific election characteristics directly impacting participation and election outcomes, such as the time of year of the election (Dunne et al., 1997; Fort and Bunn, 1998; Meredith, 2009), which can increase or decrease participation due to the election being held in conjunction with other state or national elections, or a higher likelihood of inclement weather on election day, such as during the winter in northern states, hampering the community's ability to get to the polls.
In addition, while the present study only provides evidence for the direct effects model, we hypothesize that school support attitudes are correlated with participation rates and that these together may converge in voter preference which may act on the election outcome. And finally, our work on modeling districts refloating failed bonds indicates that any broader theory should consider that each past election outcome in a community is remembered, and may influence the next election cycle not only through voter preference, but also through school support attitudes and participation and could influence administrators to change different aspects of the bond based on if the previous bond passed or failed. While we were unable to test such a mediated model here, due to the lack of both voter participation data and community school support attitudes, we propose this mediated model to help inform future theory, to encourage future studies to collect and analyze these important hypothesized mediating variables, and to help further define a contemporary theory of school bond passage.

\section{Limitations}

While we argue that the results of this study are robust, the analysis was limited in the following ways. First, the study is limited to the Texas context and the data available. While using the entire population of proposed bonds over a multi-year time span decreases sample bias and error in the population estimates, the study should still be considered a biased and intact sample, since we wish to generalize outside of Texas to the likelihood of passing a school bond in other states. Thus, controlled statistical models of cross-state comparisons are needed in this research domain to understand which parameters are context specific and which are more generalizable across the U.S. education system. In addition, other substantive variables that may influence the election outcome, such as the number of public information meetings held in the district prior to the election, as well as voter turnout and school support attitudes, were not available but could add substantially to the model. Second, we included two variables from the 2000 U.S. census, percentage population over age 65 and percentage population with a college degree, due to how they were 
reported in the CCD. Thus they were both included in the model as time invariant, when in fact both variables are changing over time. Future research should work to include the 2010 census, as well as estimates of these changing variables by year. Third, for the 1997 and 1998 bond data reported by Texas, some proposition numbers and purpose statements were reported as "no-report". After 1998 there was complete data. We chose to include both years to increase the power of the analysis which is recommended under these types of conditions (Graham, Cumsille, \& Elvira, 2003), and we addressed the issue by placing the "no-report" for proposition number in the reference group and in the "other" category for the purpose statements. Thus, both the bond characteristics and proposition number findings from the final full model should be interpreted with some caution, since the parameter estimates are both most likely somewhat upwardly biased. However, when we re-analyzed the final model excluding years 1997 and 1998 we found no substantive differences (data not shown). Fourth, variables such as median income and district long-term debt were available but were not included in the final model due to multicolinearity, mostly with percent free lunch students, tax rate and enrollment growth. We argue that percent free lunch students is a reasonable proxy of district wealth that is also measured through median income. The tax rate and long-term debt of the district were correlated, so we selected the tax rate as the broader measure of the local tax burden within the district.

The final two main limitations deal with the statistical model, namely limited dependency and unobserved heterogeneity. The sample is somewhat dependent, in that if a bond failed on the first attempt, it was eligible to not only be refloated a second or third time if a district wished to attempt the bond again, but some districts broke refloated bonds into a set of smaller bonds that substantively added up to the original. This creates a limited amount of dependency within the data, with a few bonds nested within the broken-up structure. We considered using a two-level nested discrete time hazard model, however because first float has a one to one ratio (no level 1 variance) for such a model applied to this data, we determined that such a model would not be appropriate because it would most likely be unidentified due to this data structure issue. Future research should consider analyzing two separate models to gain a greater understanding of how breaking up the bonds may influence float. We argue that such a model is beyond the scope of the current study since we were focused on extending the past models into the Texas context. However, we did test "break-up" as a categorical dichotomous variable in the final model, and it was not significant (data not shown), most likely due to the fact that upon second float $73.08 \%$ of the non-broken up bonds passed while $73.81 \%$ of the broken up bonds passed. We encourage future research to examine this issue.

The final limitation deals with unobserved heterogeneity. In hazard models, such as the present study, in which the probability of the outcome declines over the time metric, unobserved heterogeneity becomes an issue as an explanation for why the decline is occurring, in that it may be that differences in the composition of the risk set change over time due to unobserved subgroups (Singer \& Willett, 2003). Here, the conditional time metric modeled is float and refloat of a bond, and the "hazard" of it passing decreases over time. However, we argue that this is less of an issue with this model, since it is understood that there may be "types" of bonds that are more likely to pass upon first float, versus second and third. Here we have attempted to include all of the variables nominated in the literature on predicting passing rates, to help model both float and bond passage. Our purpose was in part to identify if, in Texas, floating and refloat is significant, as it was in Michigan, which is what we were able to demonstrate. If there are unobserved subgroups, this does not negate the point that float is significant and negative in the model. We leave it to future research to explore additional variables that may reveal specific unobserved types of floated and refloated bonds that would explain the float significance. In addition, we acknowledge that the vast majority of bonds were first float only $(90 \%)$, and so to test the robustness of the final discrete-time hazard model results when examining only first floats, we analyzed a first float only logistic regression model without the discrete-time hazard component and found no substantive differences in the results of the final model (data not shown).

\section{Conclusions and Recommendations for Practice}

In conclusion, we wish to offer practical advice to the large number of school district administrators working to find ways to fund much needed construction and renovations across schools in the U.S. While the direct effect of the influence of facilities on student achievement has been debated for some time, it is well known that there are specific minimum requirements of heating, lighting, safe and secure schools for adequate education (Bowers \& Urick, 2011; Earthman, 2000; Earthman \& Lemasters, 2009; Picus, Marion, Calvo, \& Glenn, 2005; Roberts, 2009; Uline \& Tschannen-Moran, 2008; Uline, Tschannen-Moran, \& Wosley, 2009). Coupled with this, there are well known and documented unmet capital facilities needs across the nation (Crampton, 2003), with a large percentage of school districts in need of renovations or new school facility construction. Given these priorities, we offer the following five recommendations for administrators. First, our model here confirmed the prior literature that refloated bonds have increasingly poor chances of passage. Thus, the first attempt is the most important, and so a district should devote the needed resources to help ensure that the bond will pass on the first attempt. Second, for Texas, like Oklahoma and Michigan, bond wording appears to be important. For Texas bonds, proposing renovations and debt refinancing appear to be successful strategies for passing a bond. As a caution, while specific requests for athletics and art facilities were not significant in the final model, the preliminary models and descriptive statistics indicate that by themselves, these two types of requests are favored less than others at the polls and we would caution against districts putting these two types of requests as individual and separate ballot measures. Third, we replicated and extended the ballot proposition number finding across states. Our findings strongly suggest that school bonds lower down on the ballot have much lower odds of passing. Together, these findings indicate that omnibus single ballot measures that include all of the needs of the district and includes renovations, that are at the top of the ballot (or are the only issue on the ballot), and are the first float, are the most likely to pass. For Texas, interesting times appear to be ahead, as what has been seen in the past research on bond passage as a constant - the percentage of voters who will vote yes - may be shifting as the demographics of the state change. However, these demographics are changing in opposing ways, as the percentage of older and retirement age citizens increases, while the percentage of non-white families and students is also increasing. In addition, the effects of the most recent recession are obvious in the most recent data, but it is difficult to predict how tastes for community self taxation in support of school facilities may change in the coming years, especially with the changing demographics.

While we were unable to include voter turnout in the Texas models, past research indicates that attempts to increase general 
voter participation and "get out the vote" efforts ends up decreasing the likelihood of passing a bond (Bauscher, 1993; Fort \& Bunn, 1998; Meredith, 2009; Silverman, 2011). Piele and Hall (1973) noted this issue, and that it provides a conundrum for the U.S. school administrator, given the general democratic ideal of voter participation. They gave five possible options for the administrator faced with this situation, in which only the third appeared tenable in that school administrators could:

1) attempt to increase general participation, assuming the larger voting pool will be more favorable; 2) attempt to discourage participation, assuming the smaller group of participants will be more favorable; 3) attempt to selectively recruit more yes voters, assuming the no vote will remain constant; 4) attempt to selectively discourage participation of no voters, assuming yes vote remains constant; 5) attempt to change the net distribution of the normal vote division from less no to more yes choices (Piele \& Hall, 1973, p.158).

Given the findings from this study and the recent literature on school bond passage, we concur with Piele and Hall, and encourage administrators to work to recruit yes voters while following the bond characteristics recommendations stated above.

\section{Acknowledgements:}

We thank W. Kyle Ingle for his thoughtful comments on an early draft of this manuscript.

\section{RECOMMENDED CITATION:}

Bowers, A.J., Lee, J. (2013) Carried or Defeated? Examining the Factors that Predict School District Bond Elections in Texas, 19982009. Educational Administration Quarterly, 49(5),732-767. doi: $\underline{10.1177 / 0013161 X 13486278}$

\section{REFERENCES:}

Alexander, A. J., \& Bass, G. V. (1974). Schools, taxes, and voter behavior: An analysis of school district property tax elections. Santa Monica, CA: RAND.

Arsen, D., Clay, T., Devaney, T., \& Fulcher-Dawson, R. (2005). Adequacy, equity, and capital spending in Michigan schools: The unfinished business of Proposal A. East Lansing, MI: Michigan State University, Education Policy Center.

Arsen, D., \& Davis, T. (2006). Taj Mahals or decaying shacks: Patterns in local school capital stock and unmet capital need. Peabody Journal of Education, 81(4), 1-22.

Barbour, E. L. (1966). Effects of socio-economic factors on school bond elections in Iowa. Ph.D., Iowa State University, Ames Iowa.

Bauscher, R. H. (1993). Winning school bonds at the polls. School and College, January, 15-16.

Beal, G. M. (1966). Iowa school bond issues data book. Ames Iowa: Iowa State University, Department of Sociology and Anthropology.

Beckham, J., \& Maiden, J. (2003). The effects of technology inclusion on school bond election success in Oklahoma. Journal of Education Finance, 28(4), 557-574.

Berkman, M. B., \& Plutzer, E. (2005). Ten thousand democracies: Politics and public opinion in America's school districts. Washington, DC: Georgetown University Press.

Blais, A. (2000). To vote or not to vote? The merits and limits of rational choice theory. Pittsburgh, PA: University of Pittsburgh Press.
Borooah, V. K. (2002). Logit and probit: Ordered and multinomial models. Thousand Oaks, CA: Sage Publications.

Boschee, F., \& Holt, C. R. (1999). School bond success: A strategy for building America's schools. Lancaster, PA: Technomic Publishing.

Bowers, A. J. (2010). Toward Addressing the Issues of Site Selection in District Effectiveness Research: A Two-Level Hierarchical Linear Growth Model. Educational Administration Quarterly, 46(3), 395-425. doi: 10.1177/0013161X10375271

Bowers, A. J., Metzger, S. A., \& Militello, M. (2010a). Knowing the odds: Parameters that predict passing or failing school district bonds. Educational Policy, 24(2), 398-420. doi: 10.1177/0895904808330169

Bowers, A. J., Metzger, S. A., \& Militello, M. (2010b). Knowing what matters: An expanded study of school bond elections in Michigan, 1998-2006. Journal of Education Finance, 35(4), 374-396. doi: 10.1353/jef.0.0024

Bowers, A. J., \& Urick, A. (2011). Does high school facility quality affect student achievement? A 2-level hierarchical linear model. Journal of Education Finance, 37(1), 72-94.

Button, J. W., \& Rosenbaum, W. A. (1989). Seeing gray: School bond issues and the aging in Florida. Research on Aging, 11(2), 158-173. doi: 10.1177/0164027589112002

Campbell, A., Converse, P. E., Miller, W. E., \& Stokes, D. E. (1964a). The American voter (Abridged ed.). New York: John Wiley and Sons.

Campbell, A., Converse, P. E., Miller, W. E., \& Stokes, D. E. (1964b). Elections and the political order. New York: John Wiley and Sons.

Carter, R. F., \& Ruggels, W. L. (1966). The structure and process of school-community relations, Volume IV. The process of school-community relations. Stanford, CA: School of Education, Stanford University.

Crampton, F. E. (2003). Unmet school infrastructure funding need as a critical educational capacity issue. In F. E. Crampton \& D. C. Thompson (Eds.), Saving America's school infrastructure: (pp. 3-26). Greenwich, CT: Information Age Publishing.

Crampton, F. E., Thompson, D. C., \& Hagey, J. M. (2001). Creating and sustaining school capacity in the twenty-first century: funding a physical environment conducive to student learning. Journal of Education Finance, 27(2), 633-652.

Davis, L., \& Tyson, B. (2003). Strategic bonding. American School Board Journal, 190(7), 34-36.

Duncombe, W., Robbins, M., \& Stonecash, J. (2003). Measuring citizen preferences for public services using surveys: Does a "gray peril" threaten funding for public education? Public Budgeting \& Finance, 23(1), 45-72. doi: 10.1111/15405850.2301003

Duncombe, W., \& Wang, W. (2009). School facilities funding and capital-outlay distribution in the states. Journal of Education Finance, 34(3), 324-350.

Dunne, S., Reed, W. R., \& Wilbanks, J. (1997). Endogenizing the median voter: Public choice goes to school. Public Choice, 93, 99-118.

Earthman, G. I. (2000). The impact of school building conditions, student achievement, and behavior The Appraisal of Investments in Educational Facilities (pp. 181-194). Paris: OECD - Organisation for Economic Co-operation and Development.

Earthman, G. I., \& Lemasters, L. K. (2009). Teacher attitudes about classroom conditions. Journal of Educational Administration, 47(3), 323-335. 
Ehrenberg, R. G., Ehrenberg, R. A., Smith, C. L., \& Zhang, L. (2004). Why do school district budget referenda fail? Educational Evaluation and Policy Analysis, 26(2), 111-125. doi: 10.3102/01623737026002111

Fort, R. (1988). The median voter, setters, and non-repeated construction bond issues. Public Choice, 56, 213-231.

Fort, R., \& Bunn, D. N. (1998). Whether one votes and how one votes. Public Choice, 95, 51-62. doi: 10.1023/A:1004934330814

Glass, G. V. (2008). Fertilizers, pills and magnetic strips: The fate of public education in American. Charlotte, NC: Information Age Publishing.

Graham, J. W., Cumsille, P. E., \& Elvira, E.-F. (2003). Methods for handling missing data. In I. B. Weiner, J. A. Schinka \& W. F. Velicer (Eds.), Handbook of psychology: Volume 2 Research methods in psychology (pp. 87-114). New York, NY: John Wiley \& Sons.

Guzmán, B. (2001). The Hispanic population: Census 2000 brief. Washington, DC: U.S. Department of Commerce Retrieved from http://www.tx.ncsu.edu/research_industry/ntcprojects/S05NS04/database/gov_studies/Hispanic_Population.pdf.

Holt, C. R. (2009). School bond success: A strategy for building America's Schools (3rd ed.): Rowman \& Littlefield Education.

Holt, C. R., Wendt, M. A., \& Smith, R. M. (2006). School bond success: An exploratory case study. Rural Educator, 27(2), 11-18.

Ingle, W. K., Johnson, P. A., \& Petroff, R. A. (2011). Estimating resource costs of levy campaigns in five Ohio school districts. Journal of Education Finance, 37(1), 52-71.

Ingle, W. K., Johnson, P. A., \& Petroff, R. A. (2012). "Hired guns" and "legitimate voices": The politics and participants of levy campaigns in five Ohio school districts. Educational Administration Quarterly, 48(5), 814-858. doi: $10.1177 / 0013161 X 12448251$

Johnson, P. A., \& Ingle, W. K. (2009). Campaign strategies and voter approval of school referenda: A mixed methods analysis. Journal of School Public Relations, 30(1), 51-71.

Kastory, R. C., \& Harrington, S. J. (1996). Voter perceptions are key to passing a school bond. Educational Research Quarterly, 20(1), 49-58.

Kraus, B. W. (2009). A descriptive analysis of selected community stakeholder opinions regarding potentially critical factors in school bond referenda success or failure in Kansas during the years 2004-2007. Ed.D. Dissertation, Kansas State University, Manhattan, Kansas. Retrieved from http://krex.kstate.edu/dspace/handle/2097/2170

Ladd, H. (1975). Local education expenditures, fiscal capacity, and the composition of the property tax base. National Tax Journal, 28(2), 145-158.

Lentz, C. (1999). Predicting school referenda outcomes: Answers from Illinois. Journal of Education Finance, 24(4), 459-482.

Lipset, S. M. (1963). Political man: The social bases of politics. New York: Anchor Books.

Mathison, T. R. (1998). Successful bond elections. School Business Affairs, 64(1), 30-33.

Meredith, M. (2009). The strategic timing of direct democracy. Economics \& Politics, 21(1), 159-177. doi: 10.1111/j.14680343.2008.00342.x

Militello, M., Metzger, S. A., \& Bowers, A. J. (2008). The high school "space race": Implications of a school-choice market environment for a Michigan metropolitan region. Education and Urban Society, 41(1), 26-54. doi: $10.1177 / 0013124508321358$

Minar, D. W. (1966). The community bases of conflict in school system politics. American Sociological Review, 31, 822-835.

NCES. (2000). Condition of America's public school facilities: 1999. Washington D.C.: Retrieved from Condition of America's public school facilities.

NCES. (n.d.). Common Core of Data Retrieved December 18, 2006, from http://nces.ed.gov/ccd/

Picus, L. O., Marion, S. F., Calvo, N., \& Glenn, W. J. (2005). Understanding the relationship between student achievement and the quality of educational facilities: Evidence from Wyoming. Peabody Journal of Education, 80(3), 71-95.

Piele, P. K., \& Hall, J. S. (1973). Budgets, bonds, and ballots: Voting behavior in school financial elections. Lexington, Mass.: Lexington Books.

Price, B. (1932, Tuesday, Feburary 16). Politics at random, Sarasota Herald, p. 7. Retrieved from http://news.google.com/newspapers?id=RJYcAAAAIBAJ\&sj id=QGQEAAAAIBAJ\&pg=2919,2809301\&dq=politics-islocal\&hl=en

Roberts, L. W. (2009). Measuring school facility conditions: an illustration of the importance of purpose. Journal of Educational Administration, 47(3), 368-380.

Rubinfeld, D. L. (1977). Voting in local school election: A micro analysis. The Review of Economics and Statistics, 59(1), 3042.

Shober, A. F. (2011). Attracting capital: Magnets, charters, and school referendum success. Journal of School Choice, 5(2). doi: 10.1080/15582159.2011.577676

Sielke, C. C. (1998). Michigan school facilities, equity issues, and voter response to bond issues following finance reform. Journal of Education Finance, 23(3), 309-322.

Sielke, C. C. (2003). Financing school infrastructure needs: An overview across the 50 states. In F. E. Crampton \& D. C. Thompson (Eds.), Saving America's school infrastructure (pp. 27-52). Greenwich, CT: Information Age Publishing.

Sielke, C. C., Dayton, J., Holmes, T., \& Jefferson, A. L. (2001). Public school finance programs of the U.S. and Canada: 1998-99. (NCES 2001309). Washington, D.C.: Retrieved from http://nces.ed.gov/edfin/state_financing.asp.

Silverman, R. M. (2011). How unwavering is support for the local property tax?: Voting on school district budgets in New York, 2003-2010. Journal of Education Finance, 36(3), 294-311. doi: 10.1353/jef.2011.0003

Singer, J. D., \& Willett, J. B. (2003). Applied longitudinal data analysis: Modeling change and event occurrence. New York: Oxford University Press.

TBRB. (n.d.). Teaxs ISD bond election database. from Texas Bond Review Board http://www.brb.state.tx.us/agency/agency.aspx

TEA. (n.d.). Academic Excellence Indicator System (AEIS). from Texas Education Agency http://ritter.tea.state.tx.us/perfreport/aeis/

Temin, P. (2010). The great recession and the great depression. National Bureau of Economic Research (NBER). Cambridge, MA. Retrieved from http://www.nber.org/papers/w15645.pdf

Uline, C. L., \& Tschannen-Moran, M. (2008). The walls speak: the interplay of quality facilities, school climate, and student achievement Journal of Educational Administration, 46(1), 55-73.

Uline, C. L., Tschannen-Moran, M., \& Wosley, T. D. (2009). The walls still speak: the stories occupants tell. Journal of Educational Administration, 47(3), 400-426. 
Zimmer, R. W., Buddin, R., Jones, J. T., \& Liu, N. (2011). What types of school capital projects are voters willing to support? Public Budgeting \& Finance, 31(1), 37-55. doi:

10.1111/j.1540-5850.2011.00973.x

Zimmer, R. W., \& Jones, J. T. (2005). Unintended consequence of centralized public school funding in Michigan education. Southern Economic Journal, 71(3), 534-544. 